\title{
REDUCTION OF AN ADVERSE IMPACT DURING WELL DRILLING BY MEANS OF DRILLING WASTE USAGE
}

\author{
Vladimir Sergeevich Kuznetsov ${ }^{1}$, Igor Konstantinovich Suprun ${ }^{1}$ \\ 1 Saint-Petersburg Mining University, 21st Vasilevsky Ostrov, Line 2, Saint Petersburg, 199106, Russia, e-mail: \\ igor_suprun@mail.ru
}

Received: 2016.10.19

Accepted: 2017.01.02

Published: 2017.03.01

\begin{abstract}
The problem of drilling waste utilisation is assumed to be resolved through the implementation of the complex of environment protection measures in production engineering. They include primarily the use in the process of well drilling of drilling mud on the basis of water-soluble biodegradable polymers and a four-stage drilling mud refining system. Secondly, the usage of the well site construction with trenching for allocation of expressed bore mud and a temporary ground tank for drilling waste water.
\end{abstract}

Keywords: bore mud, utilisation, toxicity, well site, sludge pit, dehumidification, oil production, refining, expression, waste treatment.

\section{INTRODUCTION}

The activity of oil and gas industry enterprises inevitably leads to a man-made impact on natural environment. It manifests primarily in deforestation, soil and landscape degradation, air, surface and ground water pollution and surface sediment pollution by oil products and toxic substances of the drilling mud, as well as hydrogen sulphide contained in oil and gas which leads to an adverse impact on the living conditions of people and biota.

During the well site construction process a large-tonnage waste is generated - bore mud which is subject to utilisation. Currently, over 100 000 tonnes of bore mud are formed every year only on the territory of Western Siberia. For the most part, in order to utilise it, ground tanks are constructed - the so called sludge pits which are considered to be dangerous sources of pollution.

Oil production enterprises' expenses for treatment and utilisation of bore mud and a remediation of sludge pits comprise billions of roubles every year. However, despite high ecological danger of drilling waste, so far they have not developed any process engineering solutions which would allow for its high efficiency and minimal man-made impact neutralisation and utilisation.

\section{MATERIALS AND METHODS}

The aim of this research is the reduction of environmental footprint on the ecosystem during oil and gas field development and operation at the cost of implementation of the complex of environment protection measures in production engineering directed at neutralisation and subsequent usage of the drilling waste.

The purposes of this research are as follows:

1) carrying out a complex monitoring of well sites during hydrocarbon production;

2) carrying out a chemical-analytical research of bore mud;

3) substantiation of the application of four stage drilling mud refining system with the utilisation of separated and expressed mud;

4) development of well site construction with the placement of an expressed bore mud into the back of the embankment mass;

5) assessment of ecological-economical efficiency of the application of a proposed complex of engineering and technical measures.

In the reduction of an adverse impact from drilling and well operations, alongside with the strict adherence to oil production and transportation technology and the increase of equipment 
reliability, the important part is played by the organisation of efficient control and the forecast of environment alterations in time and space - in other words, the arrangement of monitoring.

Integrated monitoring had been carried out for 6 years at one of the deposits in Western Siberia situated in a bog type landscape. Field studies were conducted with the participation of various specialists. The degree and speed of natural overgrowing of bushy eolian foreset beds and pits, the state of soil and vegetation covering, soil microbiota, entomofauna, terrestrial vertebrate species and birds, aquatic organisms (phyto- and zooplankton, zoobenthos and ichthyofauna of surrounding reservoirs) were under study and the hydrological regime of the territory was assessed. The content and properties of bore mud (drilled solids containing chemical reagents, additions and drilling fluids) were analysed. Soil organisms, plants, animals and hydrobionts were used as bioindicators.

Subsequent to the results of monitoring and analysis of the existing methods of mud pits remediation, the authors observed a necessity for the development of the drilling waste management technology which would be beneficial from the point of view of ecologinomics and, ultimately, accelerate the recovery of original biosystems or create the conditions for the occurrence of the new ones.

In substantiation of a specific utilisation method, chemical-analytical research of bore mud for determination of the content of naturally occurring radionuclides and heavy metal compounds in active forms is required. Bore mud is the main large-tonnage waste of oil producing industry. Being a variety of industrial waste, it consists of rock formation which is crushed and brought onto the daylight surface with the help of drilling mud during the drilling. Bore mud toxicity is determined by means of toxic components content in drilled solids and employed reagents.

In the Russian Federation exploitation is carried out in oil-bearing provinces whose rock formation does not contain naturally occurring radionuclides and heavy metal compounds in active forms of the above set ratios. The use of ecologically low-hazard formulations of clay and clayless drilling mud on the basis of water-soluble biodegradable polymers in all drilling intervals reduces their adverse impact as well as the toxicity of bore mud and drilling waste water. Other materials and chemical agents used for drilling mud treatment must also have toxicity indicators approved in accordance with the established procedure (MRL, SRLI, LD50, etc.) and the hazard category not exceeding 4 . When planning the usage of substances with the unknown sanitarytoxic characteristics, it is necessary to request the relevant document from the manufacturer or arrange the determination of required toxicity indicators and hazard category for materials and resultant waste.

Separation and expression of bore mud is carried out with the use of a four-stage bore mud refining system which contains high efficiency vibration screens, mud separators or shale shakerdesander, desilters and centrifuges.

\section{RESULTS AND DISCUSSIONS}

The use of this purification system allows to reduce water consumption for operating requirements by $60-75 \%$ and chemical reagents consumption by $30-40 \%$ which increases ecological safety of drilling operations and decreases a possible impact from resultant waste.

Mud, which passed a four-stage refining system, undergoes inspection concerning compliance with the standards specified in a sanitary and epidemiological inspection report. Its oil-product content should be below $0.5 \%$. Based on the results of laboratory research, decisions are taken on mud placement in the embankment of the area construction. When using drilling mud processed with reagents Kem Pas and Poly Kem D or their certified equivalents, refined (expressed) bore mud outside of submersible areas can be housed in cluster pads embankment mass.

A refined bore mud from screw-based refining system is supplied to a specially built in the embankment mass ground trench. Drilling waste water flows through to a temporary hydrolysed ground tank. The trench and the ground tank are situated parallel to each other along the well rig axis of movement. This site construction at all the stages of well site construction ensures a separate stocking of bore mud and drilling waste water (please see picture).

Well drilling with the use of drilled solids in cluster pad construction is conducted outside submersible areas. In this case, a trench is established opposite each of the well fields for the placement of refined bore mud. A temporary ground tank for drilling waste mud is established behind the trench in the embankment mass. 
During well site construction, the section for drilling waste water tank is filled up to the site project reference with the subsequent development and usage of clay in tank basin, which ensures a maximal compaction of the upper layer of peat deposits under the embankment pressure as well as maximal consolidation of the embankment itself. The bottom of the tank is raised over the maximal water-level by $0.3 \mathrm{~m}$. The hydrolysation of a temporary tank for drilling waste water is carried out with the help of a consolidated aggregate by a clay mud (Figure 1).

To collect fluid phase, they establish a pipe ring watersink with the diameter of $530 \mathrm{~mm}$ on the bar footing or lay discarded metal pipes with the diameter of 325-426 mm under a technical passage. A temporary tank construction for drilling waste water with a substantial water surface and shallow depths allows drilling waste water to achieve maximal oxygen saturation which, on an equal basis with reagent biodegradability, accel- erate the biodegradation of drilling waste water, decolorisation and discharge into a collector.

The following work types are envisaged on cluster pad with the placement of bore mud in the embankment mass: decolorisation and a pumpdown of drilling waste water and utility fluids into an oil-gathering main; levelling of bore mud in the trench with the expansion of pad surface to $25 \mathrm{~m}$ from the well mouth and carrying out the site diking; tank area planning for drilling water waste up to the marking below $0.5 \mathrm{~m}$ over the bog surface.

\section{CONCLUSION}

As a result of scientific research, it has been established that refined bore mud after its backfill into a trench serves as an additional watertight screen in case of an accidental spillage. A biological recultivation is carried out by two main ways: by means of natural regrowth activisation and

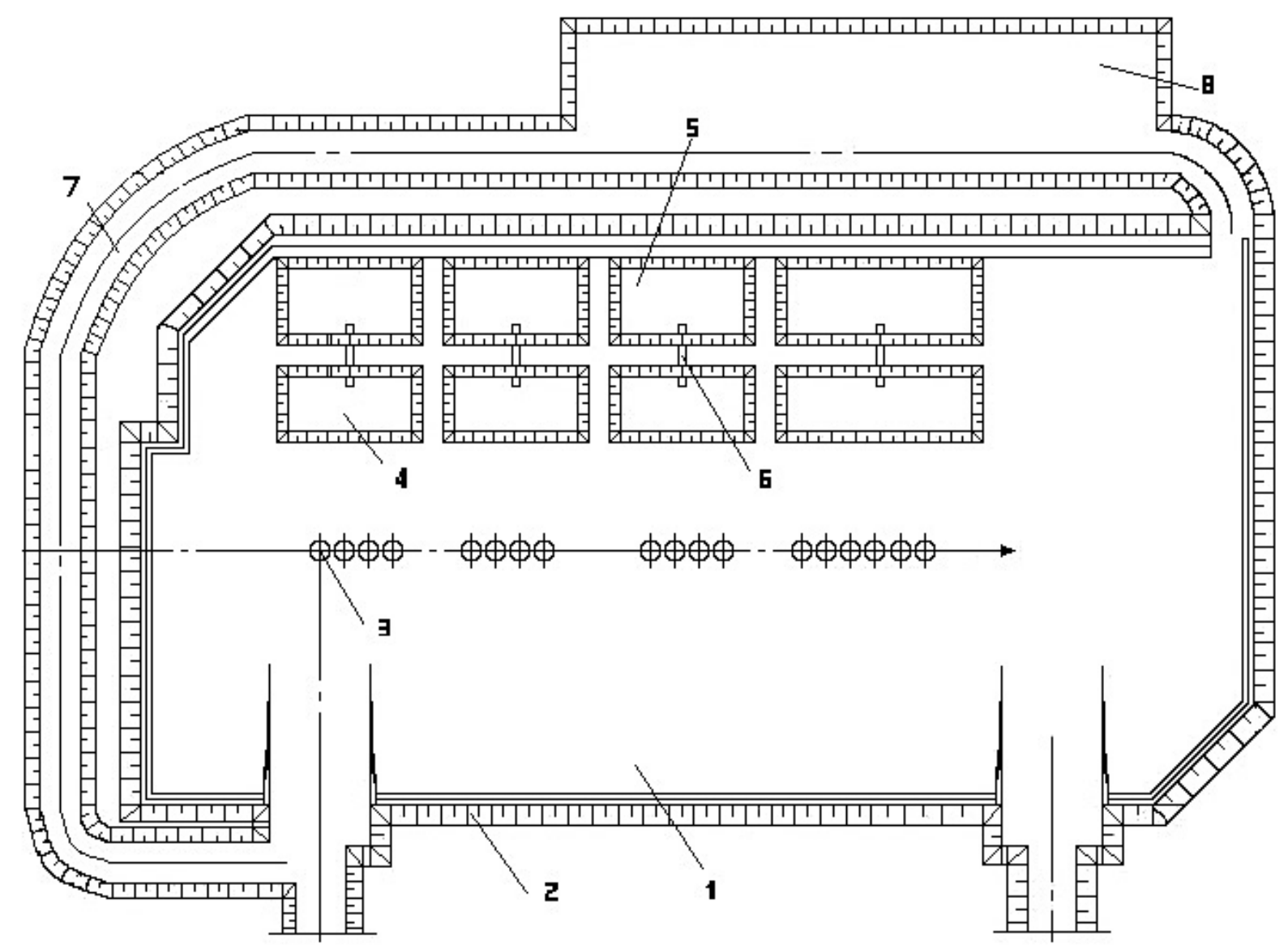

1 - well site; 2 - diking: 3 - well; 4 - a bore mud trench; 5 - a temporary ground tank for drilling waste water; 6 - metal pipes for collecting drilling waste water; 7 -the embankment of bypass road;

8 - the embankment of an inhabited area

Figure 1. The scheme of a well site with the use of drilled solids (refined bore mud) 
seeding perennial grasses, and when substantiating - by planting shrub stalks. For planting they use complex grass mixture consisting of bunch grass and rootstock grass $\left(30-50 \mathrm{~g}\right.$ for $\left.1 \mathrm{~m}^{2}\right)$ : reed fescue $(40 \%)$, red fescue $(10 \%)$, festulolium $(30 \%)$, awnless brome $(10 \%)$ and perennial ryegrass $(10 \%)$.

Compared to the known solutions, the proposed method allows to use drilling waste as clay for the construction of well site embankment and reduces the consumption of mineral ground for these purposes. The surface of the ground sections employed for drilling sites and borrow pit reduces the cost of bore mud utilisation, particularly on the well sites situated in water objects protection zones by means of the absence of bore mud transportation and the construction of sludge storage pits for its disposal.

\section{REFERENCES}

1. Bezrodnyi Y.G. 2000. Land protection in the concept of low-waste technology of well construction. Environmental Protection in the Oil and Gas Industry, 2, 15-20.

2. Bochkarev G.P., Sharipov A.U., Brahfogel E.A. 1982. Ways of disposal of waste drilling fluids. Oil Industry, 4, 64.

3. Bulatov A.I., Levshin V.A., Chemetov V.U. 1989. Methods and equipment cleaning and waste drilling. Overview Inf. Ser. Corrosion Control and Environmental Protection. VNIIOENG, pp. 56.

4. Chemetov V.Y. 1989. Cleaning drilling wastewater electrocoagulation. Overview Inf. VNIIOENG. Ser. Corrosion control and environmental protection, pp. 35.
5. Chemetov V.Y., Riabchenko V.I., Yezhov M.Yu. 1988. The use of waste drilling muds for land reclamation. EI Corrosion control and protection of the environment: Patriotican experience, 5, 12-14.

6. Kuzmin Y., Voitenko V.S., Bratishko Y. 1984. Effect of drilling fluids and their ingredients on the environment in the Far North. Oil Industry, 2, 43-49.

7. Malishkin M.M. 2009. Improved methods of reclamation of sludge pits. Notes of the Mining Institute. "Problems of subsoil" St. Petersburg RIC Mining Institute (Technical University), 181, 220-222.

8. Skomorovsky N.I., Suffering L.M., Bosov M.E. 1980. Rationing of water use in the oil industry is one of the ways to save water resources and environmental protection. Oil Industry, 2, 43-45.

9. Skomorovsky N.I., Suffering L.M. 1991. Status and trends of water resources management in the oil industry. Corrosion and Protection in the Oil and Gas Industry, 10, 22-24.

10. Shemetov V.Yu. 1989. The elimination of sludge pits at, well construction. Overview Inf. VNIIOENG. Ser. Corrosion Control and Environmental Protection, pp. 33.

11. Shishov V.A., Petrosyan M.V. 1985. Reduction of polluting properties of waste drilling fluids. Oil Industry, 2, 49-52.

12. Shitov V.A., Chemetov V.Y. 1985. Features clean reusable drilling wastewater. Oil Industry, 8, 64-66.

13. Yagafarov R.G. 1981. Influence of repeated regeneration of the active components on the properties of drilling fluids. Problems of Oil and Gas Production Tyumen, 52, 41.

14. Yakovlev V.V. 2006. Environmental safety, risk assessment. St. Petersburg Publishing NP "Strategy of the Future", pp. 476.

15. Yezhov M.Y., Terpelets V.I., Chemetov V.Y. 1987. Effect of waste drilling muds to soil pollution. VNIITEIagroprom, No. 175-BC-86. 